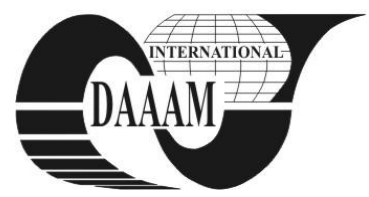

Annals of DAAAM for 2011 \& Proceedings of the 22nd International DAAAM Symposium, Volume 22, No. 1, ISSN 1726-9679 ISBN 978-3-901509-83-4, Editor B. Katalinic, Published by DAAAM International, Vienna, Austria, EU, 2011 Make Harmony between Technology and Nature, and Your Mind will Fly Free as a Bird

\title{
NEW CONCEPTS AND SOLUTIONS OF MICRO-NANO-MECHATRONICS AND MICRO-NANO-INTEGRONICS
}

\author{
GHEORGHE, I[on] G[heorghe]; CIRSTOIU, C[armen] A[driana]; ISTRITEANU, S[imona] - E[lena] \& \\ DESPA, V[eronica]
}

\begin{abstract}
The scientific paper: New Concepts and Solutions of Micro-Nano-Mecahtronics and Micro-Nano Integronics focuses on a new systemic and synergistic view of the scientific knowledge and discoveries in the high-tech field implemented in micro-nano-processing micro-nano-engineering, micronano-technologies and high competitive and high added-value micro-nano-products. The essential results of the scientific paper are materialized into the conceiving and realization of mechatronic and integronic products and systems with applicability and flexibility in intelligent fabrication systems and in measuring, verification and control products

Key words: micro-nano-mechatronics, micro-nano-integronics, intelligent measurement, micro-nano-manufacturing, micronano-engineering
\end{abstract}

\section{INTRODUCTION}

The new concepts and innovative solutions of "MicroNano-Mechatrons, $\boldsymbol{\mu n M}$ and Micro-Nano-Integronics, $\boldsymbol{\mu n I " ,}$ applied in intelligent measurement technique by integrating them into future intelligent automobile industry, are treated in a systematic and synergetic new vision of knowledge and scientific discoveries, creating new generations of advanced systems and products for industry, research and education and by integrating new mechatronic and integronic techniques and methods and also in structures of technological, scientific and industrial intelligent platforms.

In compatibility Europe 2020 and 2030, "Micro-NanoMechatronics and Micro-NanoIntegronics" is a scientific strategy for smart and environmental growth and pro/development strategy for innovation, research and education.

\section{MICRO-MECHATRONIC AND MICRO- INTEGRONIC PROCESS/ SYSTEMS, DESIGNED IN INCDMTM}

2.1 Intelligent Micro-Mechatronic Machine for Dimensional Control and Marking „Power Transfer Unit” for the Auto Subassemblies in Large Scale Series Production (Fig. 1)

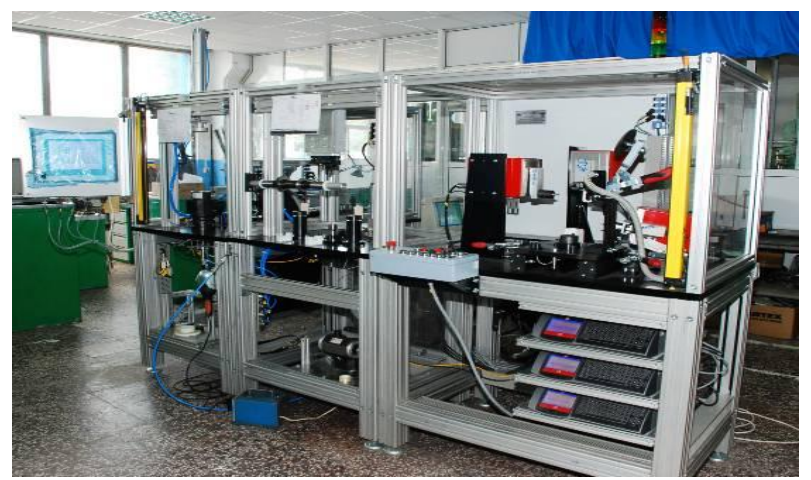

Fig. 1. Machine for dimensional control and marking "PTU" $\rightarrow$ The machine is revealed by:

- New MIX intelligent concepts (Gheorghe, 2003) in shape, structure and operating comparative with the technical European levels regarding measuring, validation and certification;

- The original technical infrastructure design, using specialized soft wares for simultaneously design (enginery competition): (AutoCAD, SolidWorks, Catia, etc.);

$\rightarrow$ Technical features:

- Time: $85 \mathrm{sec}$ (measurement + marking);

- accuracy of the measurements: $\pm 0,005 \mathrm{~mm}$;

- $100 \%$ control

2.2 Mechatronic Intelligent Unit for Tightness Cheking (Negative Pressure/ vacuum) Reverse Module TL8 Machined (Fig. 2)

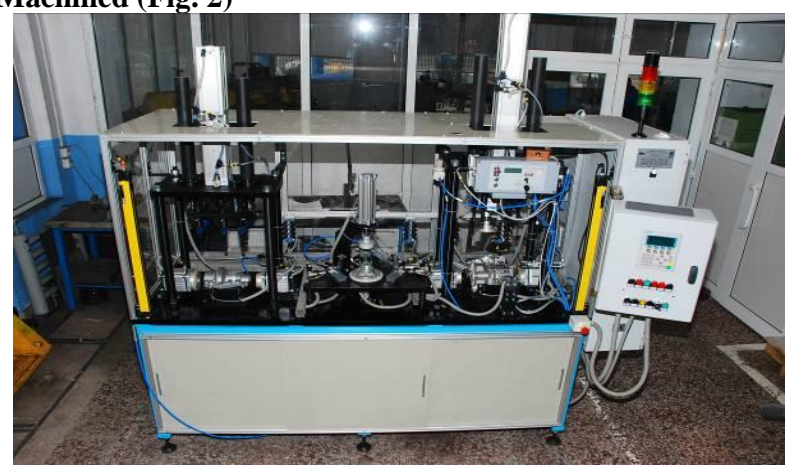

Fig. 2. Intelligent machine for dimensional control and marking

The testing intelligent unit is a mono-block construction and verifies the air loss from the pieces who composed the Reverse module (Power transfer unit).

The ATEQ-cell introduces air in the obtained cavity of the piece $(-0,5$ bar $)$; the admissible air loss must be under 0,25 $\mathrm{cm}^{3} / \mathrm{s}$;

$\rightarrow$ Technical features:

- work pressure 5 bar;

- tightness test pressure: $-0,5$ bar;

- admissible air loss: $0,25 \mathrm{~cm}^{3} / \mathrm{s}$;

- accuracy: $\pm 0,02 \mathrm{~cm}^{3} / \mathrm{s}$;

- work time/tour: $~ 40 \mathrm{sec} /$ piece

\section{MICRO-ROBOTIC SYSTEMS FOR NANO- PROCESSING AND MICRO-POSITIONING}

\subsection{Robotic, micro and nano-robotic MEMS \& NEMS}

Robotic, micro and nano-robotic MEMS \& NEMS (Fatikow et al., 1999), ensure the future and the evolution of development technologies, micro and nanotechnologies, as follows: systems and technologies for micro-nanopositionings and micronanomeasuring, principles and new concepts in "hybrid precise system" for systems and technologies at micro and nano scale. 
3.1.1 Cartesian nanomanipulator with nanometer resolution, presented in Fig. 3.
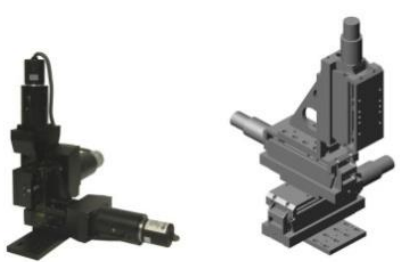

Fig. 3. 3D Nanomanipulators

Technical and functional characterization:

- increment displacement: $0.4 \mathrm{~nm}$

- the range: $10 \div 100 \mathrm{~mm}$

- working speed: $2000 \mathrm{~m} / \mathrm{s}$.

\subsection{Intelligent robotic mechatronic systems}

3.2.1 Intelligent mechatronic robotic center for micro-processing in mechatronic industry (Fig. 4)

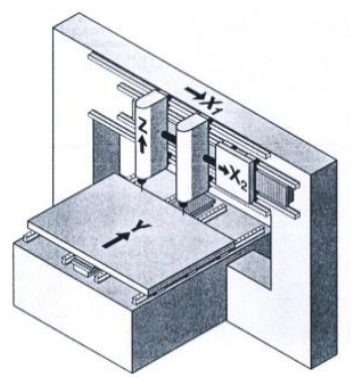

Fig. 4. Mechatronics robotic center for industrial processing

\subsection{Research on the hexapod robot}

3.3.1 Applications in Medical Mechatronics

In the figures below (Fig. 5, 6 and 7), are shown medical nanorobots working.

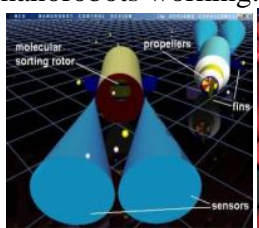

Fig. 5. Nanorobot 1

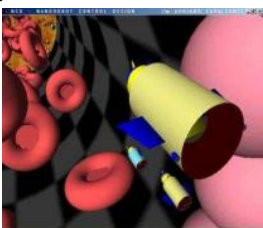

Fig. 6. Nanorobot 2

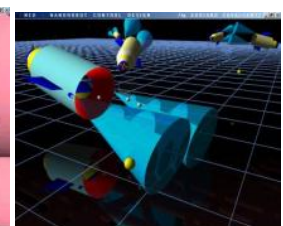

Fig. 7. Nanorobot 3

\subsubsection{Applications in integronic robotics}

Therefore, the realization and development of integronic robotics characterizes scientific orientation at the junction of several sciences, not missing biomechanics, precision mechanics, mechatronics and control and theory.

\subsubsection{Research on the hexapod micro-robot}

(a) Micro-robotic system description (fig. 8)
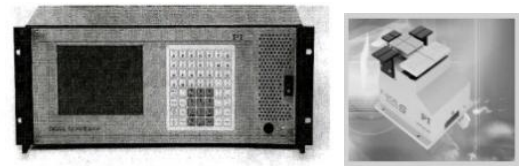

Fig. 8. Hexapod micro-robot

(b) The Mechanics of the hexapod robotic system

(c) Synchronizing movement on the 6-axis robotic system

(d) The electronics of the Hexapod robotic system

(e) The informatics of the hexapod robotic system

(f) Communication with the controller in a hexapod robotic system

(g) RS-232 connection to the hexapod robotic system

(h) TCP / IP connection

(i) The hexapod robotic coordinate system

If the pivot value is $(0,0,0)$, it is located relative to the platform as shown in Fig. 9.
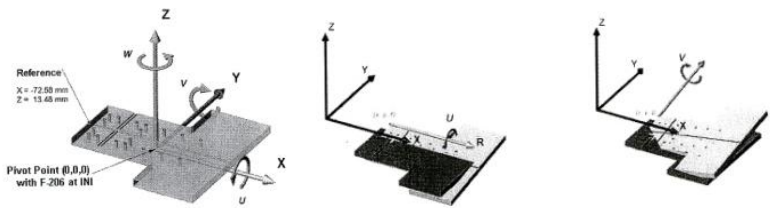

Fig. 9. Relative position of the robotic platform from origin
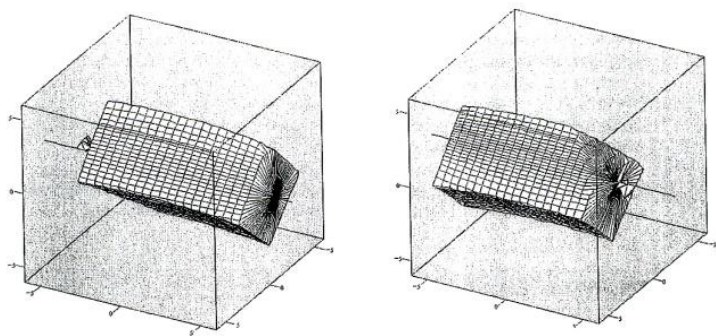

Fig. 10. Hexapod robotic system workspace

\section{RESEARCH CONTRIBUTIONS PERSPECTIVES}

The research activities related to the paper, were based on scientific hypothesis of conception, implementation, experimentation mechatronics solutions for equipments and intelligent systems for integrated control in automotive industry, for modelling micro-systems and nano-robots with application in mechatronics and in medicine and for analysis, testing and application of the hexapod micro-robot. The following research will be focused on:

- conception, realisation and implementation of new microsystems, integronic microequipments with application in manufacturing processes that take place in clean rooms;

- conception, realisation and implementation of micro-tools and micro-nanorobotics microdevices with possibilies for modernizing phisycal and laborator medical processes.

\section{CONCLUSIONS}

The conclusions of the scientific paper highlight the following aspects:

- The conceiving and defining new micro-nano-mechatronic and micro-nano-integronic fields;

- The creation of new generations of high-tech mecahtronic and integronic systems and products.

\section{REFERENCES}

Fatikow, S., Magnussen, B. and Rembold, U. A Piezoelectric mobile robot for handling of microobjects. Proceedings of the International Symposium and Microsystems, Intelligent Materials and Robots (MMIR), Sendai, 1995, pp. 189-192.

Fatikow, S., Rembold, U. Microsystems technology and microrobotics. Bucharest Technical Editure, 1999

Dexler, E. et al. Unbonding the future: The Nanotechnology Revolution, William Morrow Verl., New York, 1991

Gh. Gheorghe, D.D. Palade, Ulm Spineanu, Valentin Pau. Precision mechanics, Mechatronics and Integronics Engineer's Handbook. 2006 -ISBN-10: 973-87042-6-X, ISBN-13: 978-973-87042-6-8

Gh. Gheorghe. Integrated Mechatronics - Integronics - 2003 ISBN 973-99591-0-5 | 973 - 99591-8-0 